\title{
NUMERICAL INVESTIGATIONS ON THE STATIC STIFFNESS OF INDUSTRIAL BALL BEARING LINEAR GUIDES
}

\author{
Rahmani Mahdi, Krall Stephan, Bleicher Friedrich \\ Vienna University of Technology, Faculty of Mechanical and Industrial Engineering, Institute for Production \\ Engineering and Laser Technology, Landstraßer Hauptstraße 152, 1030 Vienna, AUSTRIA
}

\begin{abstract}
A technology of creating of geographically distributed multi-operator control of mechatronic devices via the Internet is This research work deals with some numerical investigations on the static stiffness of machine tools ball bearing linear guides. Finite Elements Method (FEM) is employed to carry out the simulations using ANSYS software. Previously, we have conducted some experimental researches of the guide's stiffness in different directions such as radial, lateral and angular directions. As experimental researches cost a lot of time and money, it is necessary to use numerical methods at the design stage and also for further investigations. Therefore, more data are available and the experiments can be concentrated to the most important fields. In this work a FEM model of the guides is developed and the results are compared to the experimental ones. A good agreement has been found to be between the experimental and numerical results.
\end{abstract}

Keywords: Static stiffness, FEM, Machine Tools, Linear Guides, Modelling
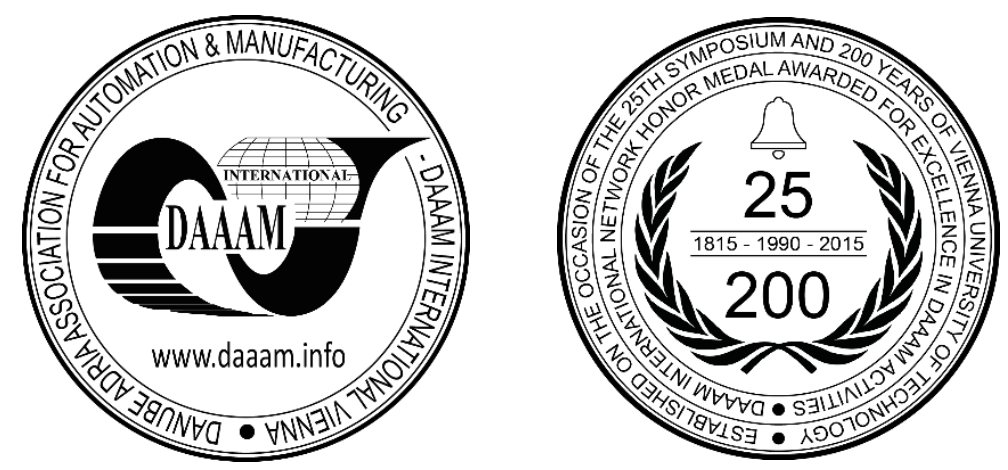

This Publication has to be referred as: Rahmani, M[ahdi]; Krall, S[tephan] \& Bleicher, F[riedrich] (2016). Numerical investigations on the static stiffness of industrial ball bearing linear guides, Proceedings of the 26th DAAAM International Symposium, pp.0608-0613, B. Katalinic (Ed.), Published by DAAAM International, ISBN 978-3-902734-07-5, ISSN 1726-9679, Vienna, Austria

DOI: $10.2507 / 26$ th.daaam.proceedings.082 


\section{Introduction}

In today's high competitive manufacturing environment the demands for higher levels of quality and safety with lower costs and manufacturing times are increasing. To fulfil these requirements more attention has to be made to the design stage and research and developments activities. Numerical modelling is one of the most important methods used to achieve this aim. With the improvements occurred during the last years in the computational resources, they can be employed to model various sophisticated processes.

Machining operations have been the core of the manufacturing industry [1]. As a result, the factors involved in machine tools influencing their performance should be thoroughly investigated. Stiffness or rigidity is one of them which should be measured for different body elements such as guides, bearings, tool holder, etc. Several investigations have been carried out on different aspects of machine tools guiding systems. Static stiffness and friction behaviour of the guides are investigated experimentally $[2,3]$. Numerical and experimental studies have been conducted regarding the effect of guide's rigidity on the joints kinematic errors $[4,5]$. Numerical and analytical modelling of linear guide systems has been conducted using component oriented FEM [6]. The influence of over determination on the performance of the guides is experimentally investigated [7]. Some researchers have studied about the stiffness Spindle Bearing System (SBS) in machine tools [8].

\section{Experimental procedure and specifications}

Previously, we have investigated on the static stiffness properties of the linear guides experimentally and analytically [9], based on which this FEM modeling is conducted and the results will be compared with the experiments. The static stiffness of the linear motion guide system in radial, reverse radial, lateral directions and the angular stiffness in roll, pitch and yaw directions were investigated. The experimental setup used for this research is illustrated in Fig. 1. The linear guides used in the experiments are ball bearing type with the model HSR 30A from the company THK. Some of the important specifications of the guide and the test bench are provided in table 1.

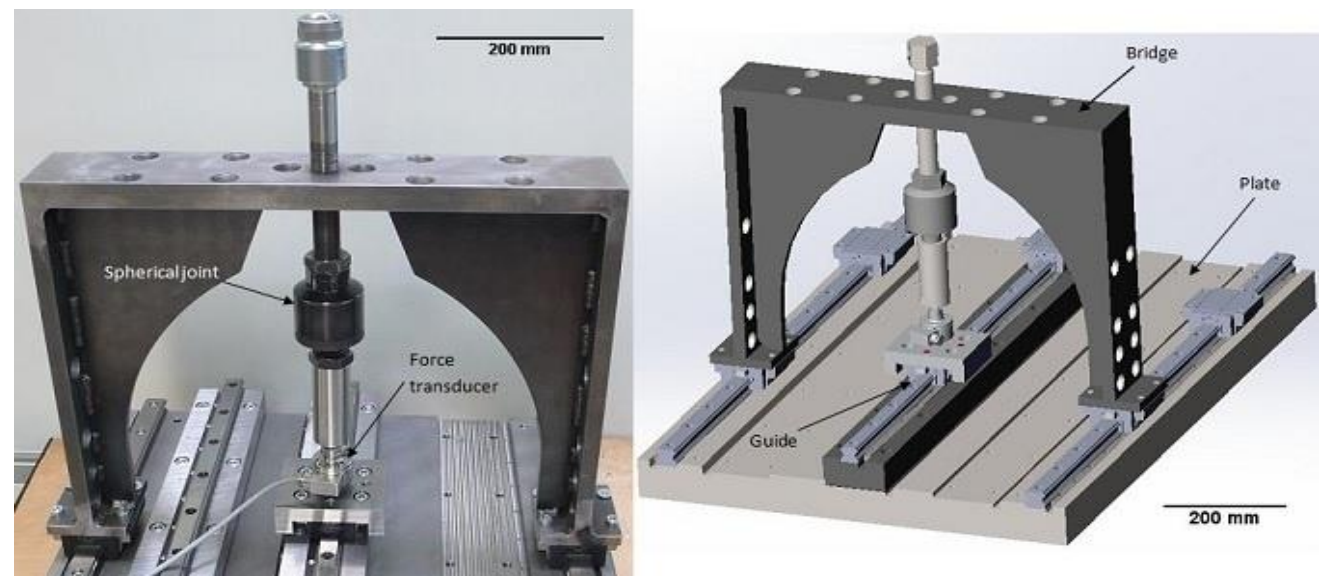

Fig. 1. The experimental setup for the experiments [9].

\begin{tabular}{ll}
\hline Component specifications & Dimensions \\
\hline Rail length & $1000 \mathrm{~mm}$ \\
Rail width & $28 \mathrm{~mm}$ \\
Carriage length & $98 \mathrm{~mm}$ \\
Carriage width & $90 \mathrm{~mm}$ \\
Ball diameter & $5.78 \mathrm{~mm}$ \\
Basic static load rating & $46.8 \mathrm{kN}$ \\
Basic dynamic load rating & $28 \mathrm{kN}$ \\
Static permissible moment (pitch and yaw) & $0.524 \mathrm{kNm}$ \\
Static permissible moment (roll) & $0.562 \mathrm{kNm}$ \\
\hline
\end{tabular}

Table 1. Ball bearing linear guide specifications [10]

\section{Modeling of the guide}

To model the linear guides, the Finite Elements Method (FEM) has been used. At first, the main components of the guide consisting of the rail, the carriage and the ball bearings are modeled as solid elements. Four rows of rolling 
elements are serving for the stiffness of the guide. Each of them is consisting of 14 ball bearings and therefore, 56 rolling balls carry the external loads. It is clear that the problems containing such a number of contacting elements need a considerable computational capacity to be efficiently modeled. In this research, a full 3D finite element model of the guide is developed. The model consists of 58 parts and 116 contacting surfaces between the rolling elements and the rail and also between rolling elements and the carriage grooves. To simplify the model and reduce the unnecessary computational time the bore holes and screws are not included in it. The CAD model is shown in Fig. 2.

The ball bearings are designated to be the contact body while the rail and the carriage were the target body in the contact settings. These designations define which two pairs of surfaces can come into contact with one another [11]. The behaviour has set to be symmetric to prevent the penetration of the contact and target surfaces to each other. Two kinds of contact conditions have been considered in the simulations. At first, the contacting bodies are considered to be in contact with friction. These simulations have led to large displacements and the results did not seem to be true. Then, they are bonded to each other. As the rolling elements are not supposed to slide under the external loads, the assumption seems to be logic but it has led to some larger values of static stiffness. For contact formulations, augmented Lagrange method has been used which in one hand is less sensitive to the magnitude of the contact stiffness and on the other hand prevents the chattering issue of the normal Lagrange method [11]. With the first simulations it was observed that the deformations occurred on the rail are negligible in comparison to that of carriage and the ball bearings. Accordingly, the size of the mesh applied for the balls and the carriage are much smaller than that of the rail.

The bottom surfaces of the rail are fixed and constrained to all kinds of DOF. A radial force of up to $10 \mathrm{kN}$ is applied on the upper surface of the runner block.

\section{Simulation results and discussions}

The results of the static stiffness for radial direction are shown in Fig. 3. More linearity can be seen in the FEM results, especially for the guide without preload. The maximum deflections are about $33 \mu \mathrm{m}$ for the experimental method and $29.5 \mu \mathrm{m}$ for the numerical ones. Therefore, there is a difference of about 11 percent between two methods.

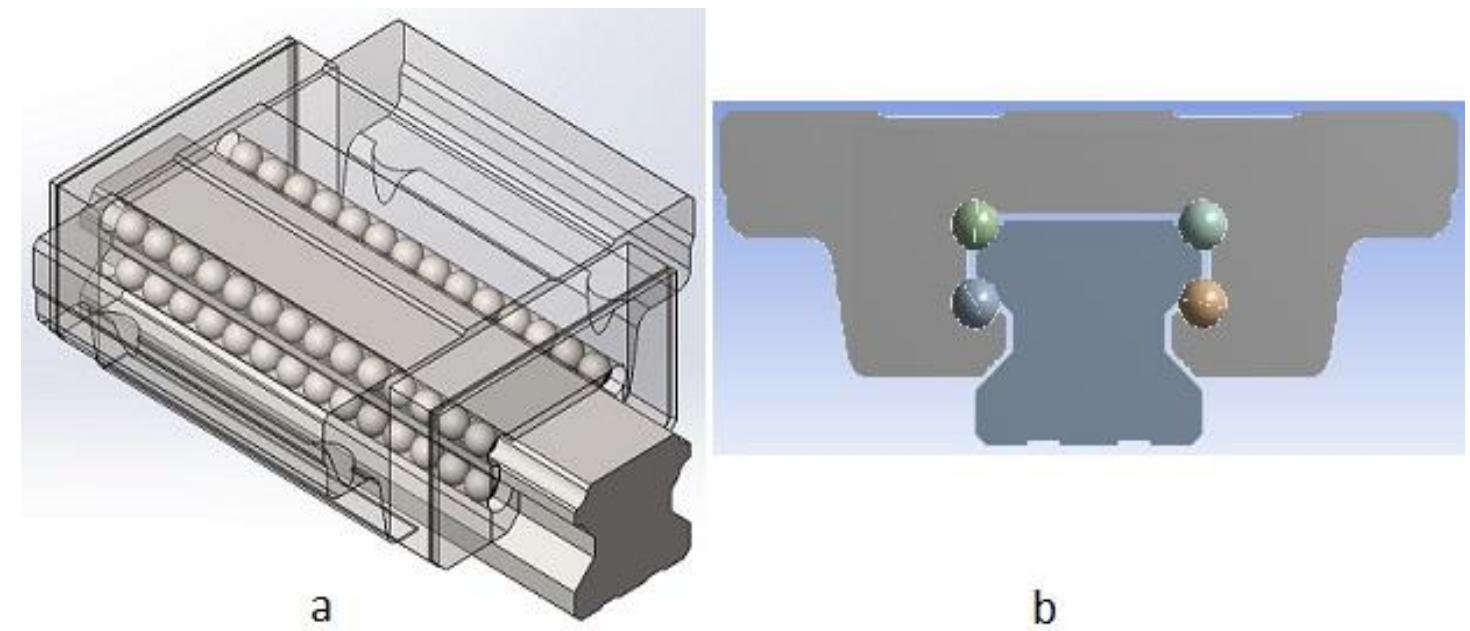

Fig. 2. (a) CAD model with the carriage transparent; (b) Side view of the model

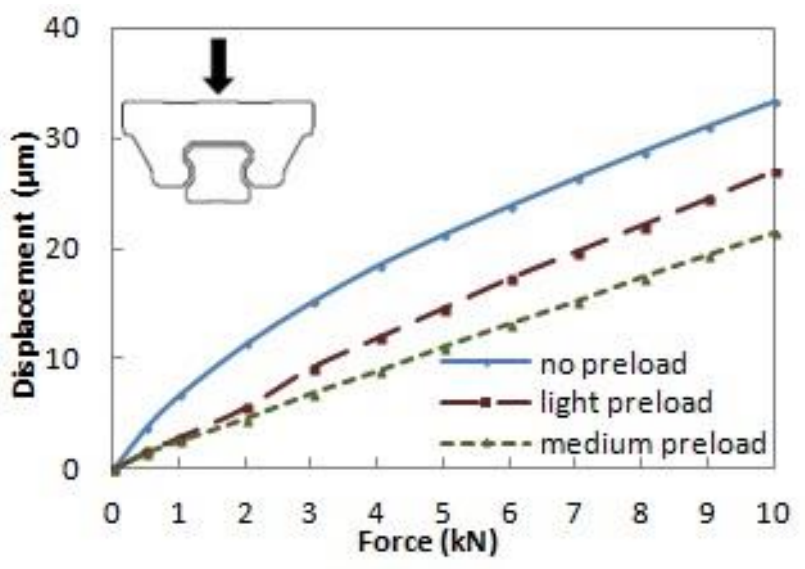

a

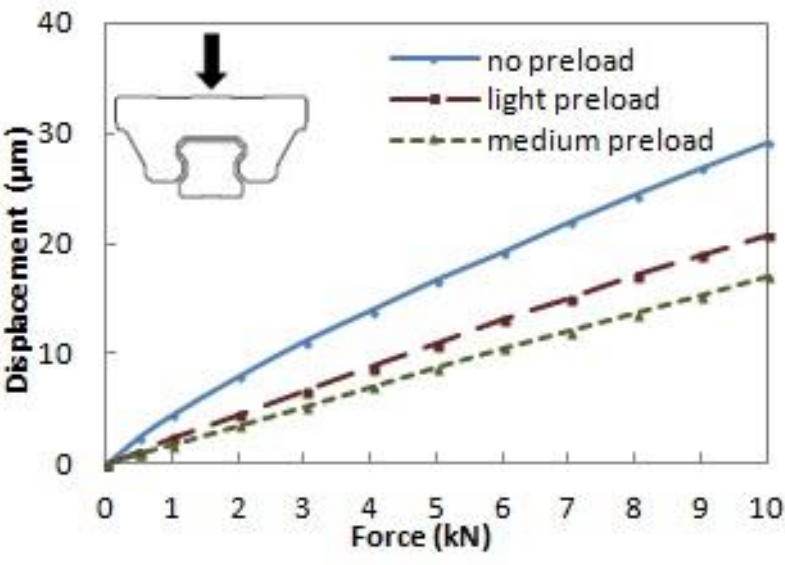

b

Fig. 3. Comparison of the force-displacement results for radial direction: (a) Experiments; (b) FEM. 
As it can be seen in Fig. 4 the force deflection curves obtained with numerical simulations are more linear than experimental ones. This may be due to the limitations in computational resources to the size of meshing. The maximum displacements measured for the not preloaded carriages under an external load of $10 \mathrm{kN}$ were about $52.4 \mu \mathrm{m}$ and $46 \mu \mathrm{m}$ for experimental and numerical methods, respectively. A difference of about 12 percent is found to be between the results.

The same experimental and FEM investigations have been conducted for the static stiffness in lateral direction and the findings are presented in Fig. 5. More similarity of the curves can be observed in these results and the deflection values are also in comparison with radial and reverse radial directions closer to each other. The maximum displacements measured for the guides without preload were about $75 \mu \mathrm{m}$ and $68 \mu \mathrm{m}$ for experimental and FEM results, respectively. That leads to a difference of about 9 percent between the results.

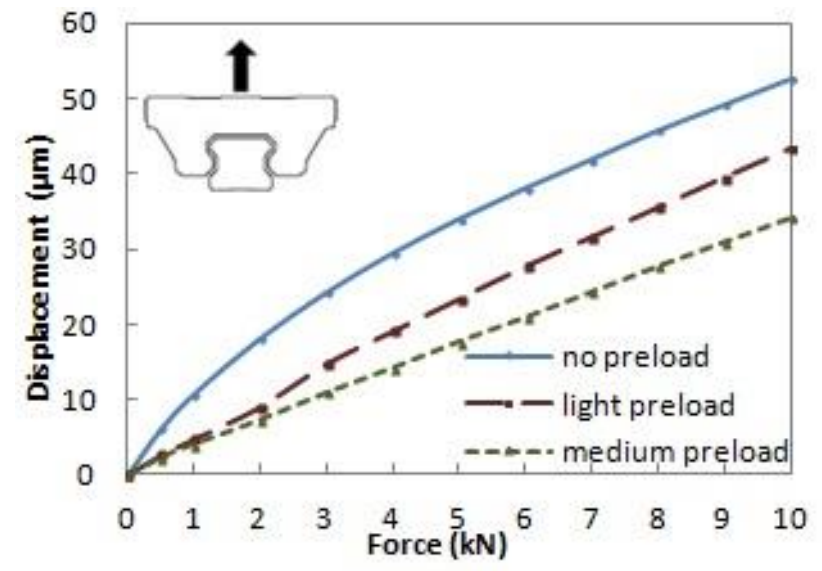

a

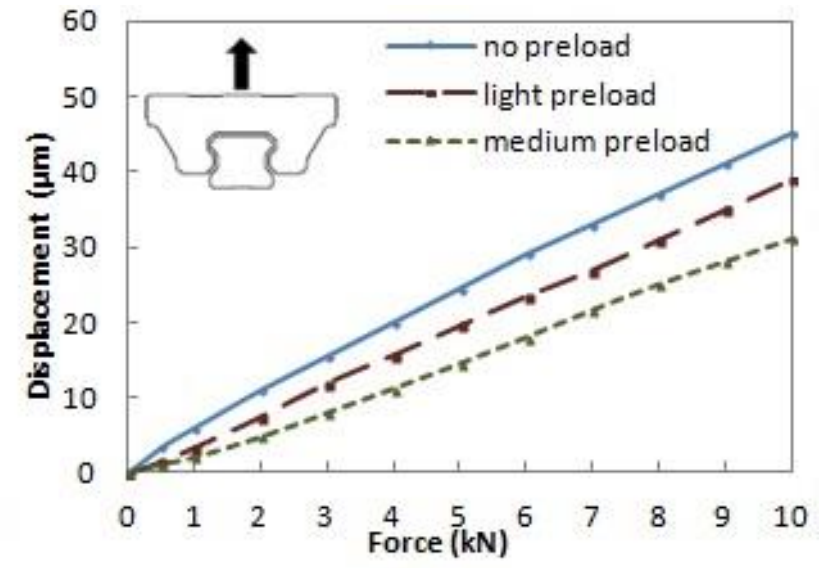

b

Fig. 4. Comparison of the results for reverse radial direction: (a) Experiments; (b) FEM.

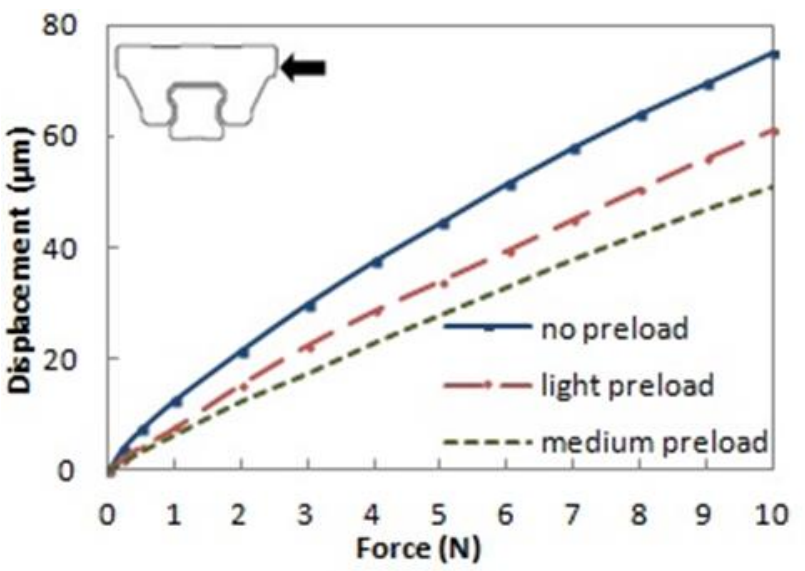

a

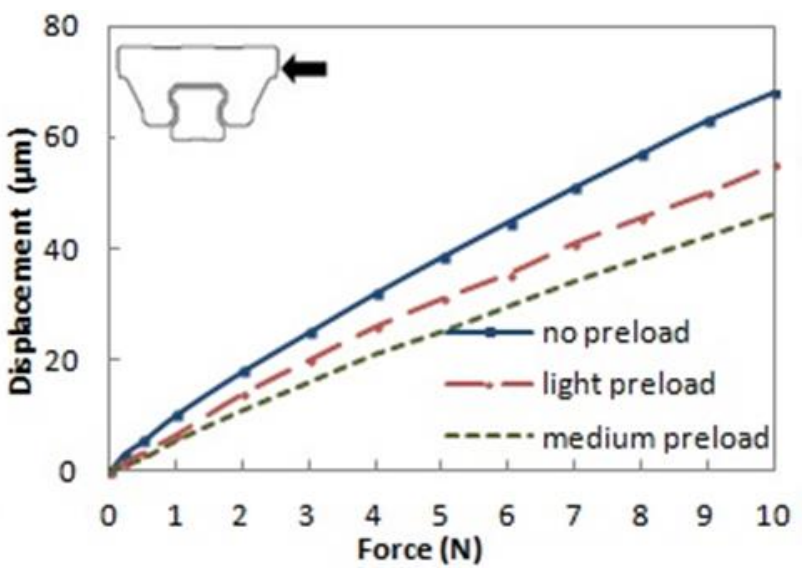

b

Fig. 5. Comparison of the load-deflections for lateral direction: (a) Experiments; (b) FEM.

A moment of up to $0.4 \mathrm{kN}$.m is applied to the guides in various angular directions of pitch, yaw and roll. The results of angular stiffness in pitch direction are shown in Fig. 6. The values of deflections obtained through the numerical simulations are larger than experimental ones. While for the not preloaded guide and under a moment of $0.4 \mathrm{kN}$.m an angular deflection of 12.7 seconds has been measured in experiments, the value obtained in FEM simulations was 14.1 seconds. The difference between the two methods results were near 10 percent.

The angular stiffness values for yaw direction are provided in Fig. 7. It is clear that the guide has larger values of stiffness in this direction. The maximum angular deflections under a moment of $0.4 \mathrm{kN}$.m were measured to be about 8 arc seconds for the experimental investigations while it was found to be about 10.2 in the FEM model. The difference between them was near 21 percent which is the largest difference in all the directions.

The last investigations have been carried out for the angular stiffness in roll direction. The deflections values are larger than those in pitch and yaw directions (Fig. 8). With the experiments a maximum angular deflection of 37.4 arc seconds is measured for the carriage without preload, while this value is 40 arc seconds in the simulations. Therefore, there is a difference of about 7 percent between the results and also the roll angular stiffness is less than pitch and yaw ones. 


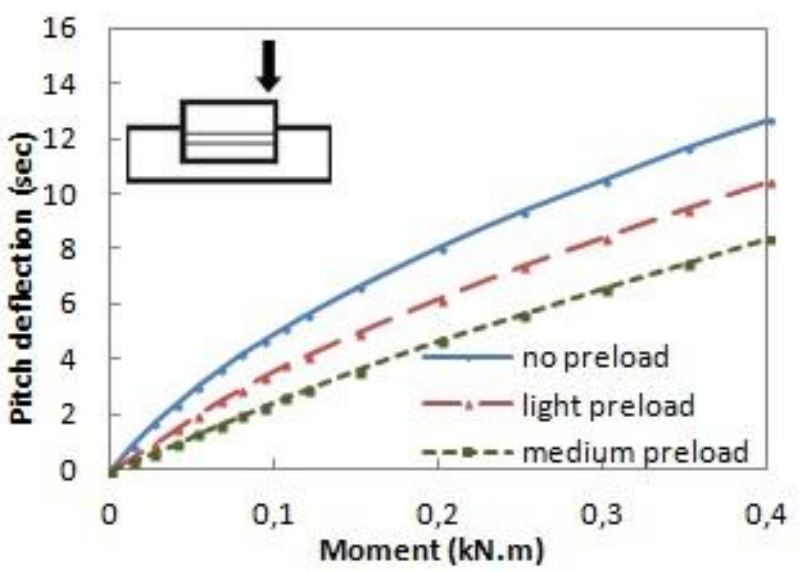

a

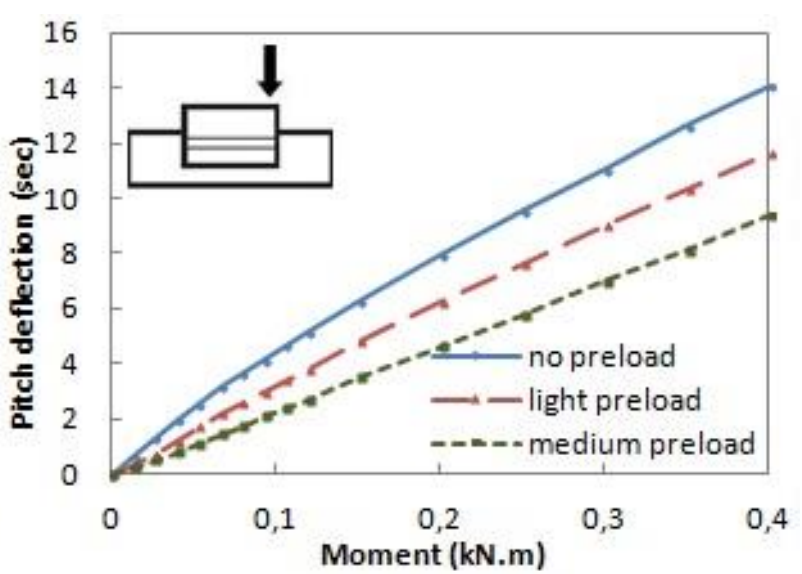

b

Fig. 6. Pitch angular stiffness results compared for two methods: (a) Experiments; (b) FEM.

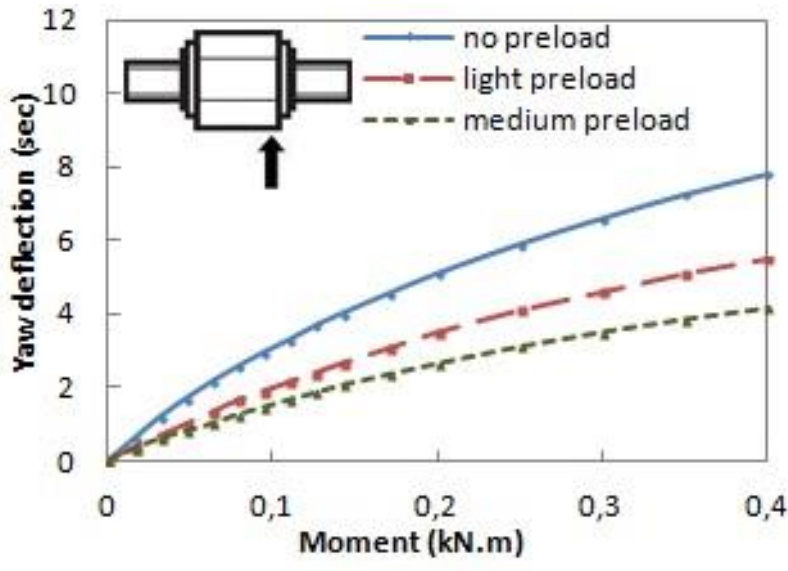

a

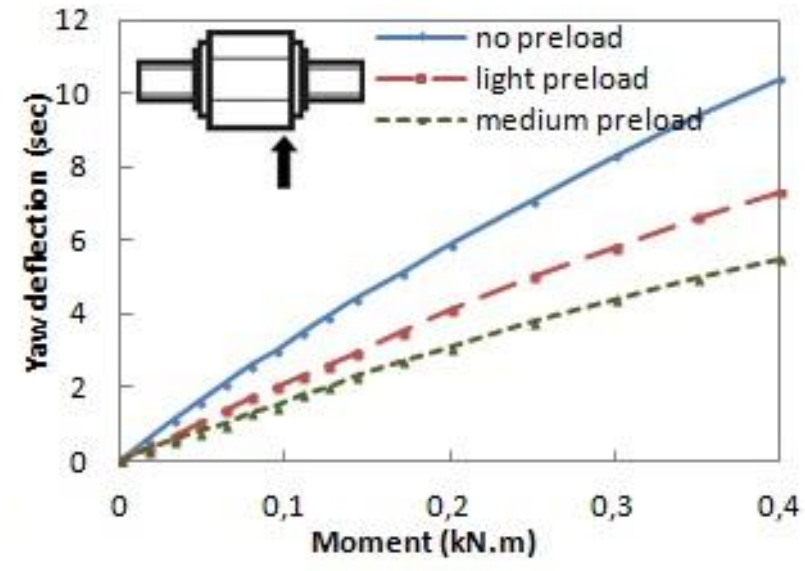

b

Fig. 7. Comparison of yaw angular stiffness for two methods: (a) Experiments; (b) FEM.

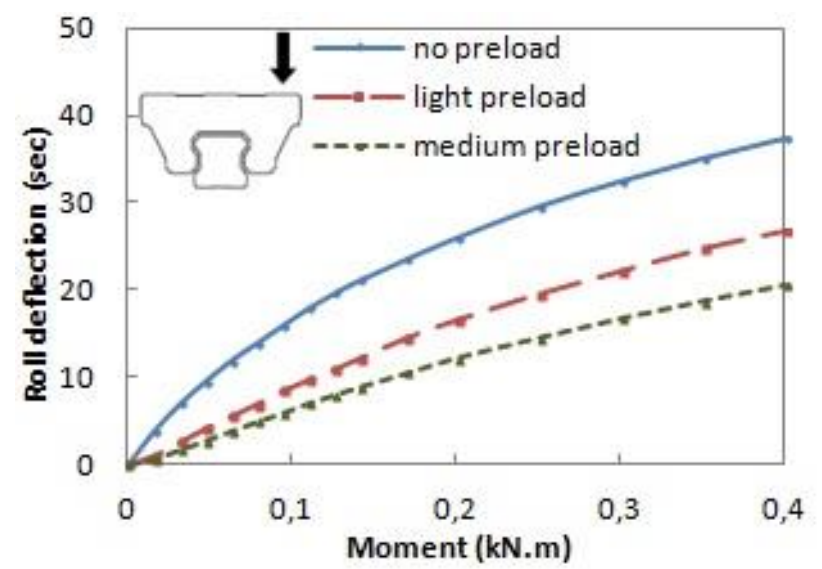

a

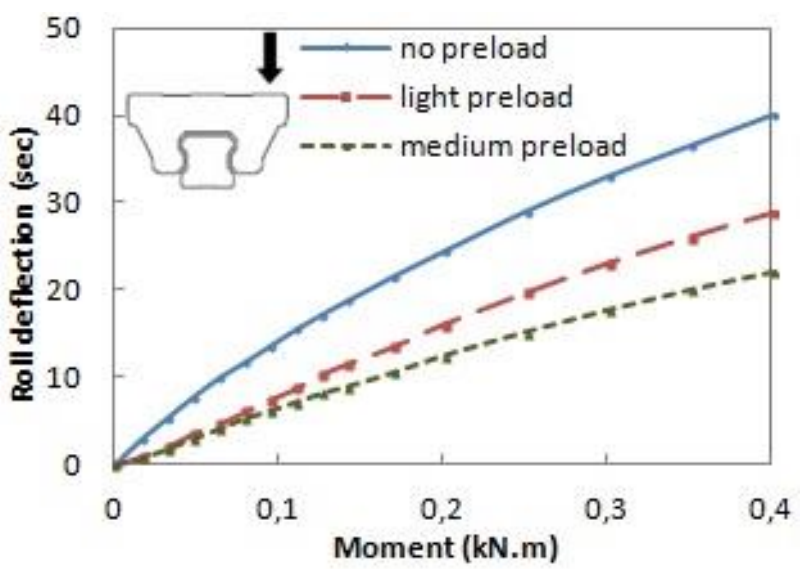

b

Fig. 8. Roll angular stiffness findings compared for: (a) Experiments; (b) FEM.

\section{Conclusions}

Based on the numerical investigations carried out on static characteristics of the ball bearing linear guides, and their comparison with the experimental results of our previous researches the conclusions can be summarized as follow:

- Static stiffness is an important nonlinear characteristic of linear guides.

- The numerical and experimental results obtained from this and previous research works are more or less in a good agreement with each other. The numerical results are more linear than the experimental ones which may be due to the limitations in the number of meshing. 
- The static stiffness in radial and angular stiffness in yaw directions are found to have the largest values.

In this research the effort was concentrated on the static characteristics of the guiding system. To complete the research, it is planned to do some dynamic investigations regarding the damping behaviour of the guides under different preloads and external forces.

\section{References}

[1] R. V. Rao, Advanced Modeling and Optimization of Manufacturing Processes, Springer-Verlag London Limited, 2011.

[2] M. Rahmani, R. Zisser-Pfeifer, S. Krall and F. Bleicher, Experimental investigation on static stiffness and friction behavior of ball bearing linear motion guides, 31st Danubia-Adria Symposium on Advances in Experimental Mechanics, September 2014, pp. 207-208.

[3] M. Rahmani, S. Krall and F. Bleicher, Experimental investigations on stick-slip phenomenon and friction characteristics of linear guides, Procedia Engineering 100, pp. 1023-1031, 2015.

[4] P. Majda, Modeling of geometric errors of linear guideway and their influence on joint kinematic error in machine tools, Precision Engineering 36, p. 369- 378, 2012.

[5] M. Rahmani and F. Bleicher, Experimental and numerical studies of the influence of geometric deviations in the performance of machine tools linear guides, In press, Procedia CIRP.

[6] A. Dadalau, K. Groh, M. Reuß and A. Verl, Modeling linear guide systems with CoFEM - Equivalent models for rolling contact, Stuttgart Research Centre for Simulation Technology (SRC SimTech), no. 2009-1, 2011.

[7] M. Rahmani and F. Bleicher, Experimental investigation of overdetermination in machine tools linear guides, 32nd DAS symposium on advances in experimental mechanics, pp. 112-113, 2015.

[8] L. Šooš, S. Ďuriš and R. Palenčár, "New Design "Duplo-Headstock"," Procedia Engineering 69, pp. 1336-1344, 2014.

[9] M. Rahmani and F. Bleicher, Analytical and Experimental Investigations on Nonlinear Static Properties of Machine Tools Guiding Systems, In press..Procedia CIRP.

[10] THK CO., LTD., General Catalog, Linear Motion Systems, Japan: THK CO., LTD., 2006.

[11] ANSYS, Inc. Proprietary, ANSYS Mechanical Structural Nonlinearities, ANSYS Customer Training Material, 2010. 